\title{
A TROCA TRANSCENDENTAL - ANÁLISE DE UM CONCEITO CENTRAL NA TEORIA DE OTFRIED HÖFFE
}

Thomas Kesselring*

SINTESE - Este artigo discute um dos pontos fundamentais da Ética de Otfried Höffe: a questão da troca transcendental. O autor, após a reconstrução da argumentação de Höffe no tocante à fundamentação dos direitos humanos, procura relacionar essa questão com o debate sobre o comunitarismo. Sustenta a tese de que nem o liberalismo nem o comunitarismo servem de base para a fundamentação de tais direitos. PALAVRAS-CHAVE - Höffe. Direitos humanos. Troca transcendental
ABSTRACT - This paper discusses one of the fundamental issues in Otfrid Höffe's Ethics: the issue of transcendental exchange. After reconstructing the rationale with which Hoffe aims at providing the philosophical foundations for human rights, the author seeks to establish the relationship between that issue and the dispute concerning communitarianism. The author concludes that neither liberalism nor communitarianism can provide us with a foundation for those rights.

KEY WORDS - Hoffe. Human rights. Transcendental exchange.

No presente trabalho, gostaria de fazer duas coisas: primeiro, reconstruir a tentativa höffeana de fundamentar os direitos humanos, e, segundo, relacionar a questão dos direitos humanos com o debate sobre o comunitarismo. Defenderei a tese de que os direitos humanos não podem ser fundamentados nem na base do comunitarismo nem na base de um liberalismo individualista no sentido estrito. A dificuldade de fundamentar os direitos humanos a partir de uma posição comunitarista é evidente: posto que esses direitos são direitos individuais e universais, toda base comunitarista - crença ou prática coletiva como tal - pelo fato de ela não ser universal, não serve para uma tal fundamentação. No entanto, o ponto de partida oposto tampouco se presta para uma tal fundamentação. Esta tese talvez seja menos evidente. Vou defendê-la analisando a teoria da troca transcendental em Höffe.

* Doutor e livre docente em Filosofia. Vive na Suíça.

\begin{tabular}{|l|l|l|l|l|l|}
\hline VERTTAS & Porto Alegre & v. 46 & n. 1 & Março 2001 & p. 29-33 \\
\hline
\end{tabular}


Otfried Höffe usa o conceito de troca transcendental para explicar e legitimar a idéia dos direitos humanos. ${ }^{1}$ Neste artigo, gostaria de reconstruir o fio condutor do pensamento de Höffe e parcialmente avaliar a sua teoria da chamada "troca transcendental".

1. Pelo fato de os direitos humanos serem de natureza universal, a base para sua fundamentação não pode depender de pressupostos particulares. A base da fundamentação deve, de qualquer forma, corresponder à natureza universal dos direitos humanos. Sendo que esses direitos têm algo a ver com a natureza humana, com a antropologia humana, essa antropologia deve abrir mão do caráter universal dos direitos humanos. É preciso, então, procurar algum aspecto universal na natureza humana.

2. Para Höffe, este aspecto é o interesse na liberdade da ação. Ele chama esse interesse de "transcendental", pois argumenta que ele é a condição necessária para que o indivíduo esteja disposto a realizar ou tentar realizar todos os outros interesses que ele tem.

Segundo Höffe, o indivíduo vive num mundo conflituoso, num mundo no qual ele deve defender os seus interesses contra os interesses dos seus pares. Com essa tese, Höffe pretende partir de uma antropologia válida universalmente - uma antropologia que se caracteriza por dois aspectos que, segundo este autor, são também válidos universalmente.

a) O indivíduo, por natureza, é muito mais um átomo no sentido de Hobbes, lutando por si mesmo, do que um animal social ou político, no sentido de Aristóteles.

b) Em contraposição àquilo que Hobbes diz, no entanto, o indivíduo não luta em primeiro lugar pela sua sobrevivência, mas sim pela sua liberdade de ação.

Para Höffe, então, o interesse na liberdade da ação é mais abrangente, mais fundamental de que o interesse na sobrevivência, pois há pessoas que preferem sacrificar a vida delas por fins e valores superiores, e este sacrifício pressupõe a liberdade de ação.

3. A idéia da assim chamada troca transcendental é introduzida para fundamentar os direitos humanos. Tentarei explicar esse conceito, baseando-me num exemplo que Höffe dá:" "No caso do direito humano primário (por razões sistemáticas), a saber, do interesse à proteção da vida, troca-se renúncias à liberdade: em caso de conflito, cada um renuncia ao seu direito de matar seus pares".

\footnotetext{
Otfried Höffe, "Ein transzendentaler Tausch: Zur Anthropologie der Menschenrechte". In: Philosophisches Jahrbuch, 99/1, 1992, p.1-28. Reimpresso sob o titulo "Transzendentaler Tausch - eine Legitimationsfigur für die Menschenrechte?" In: S. Gosepath / G.Lohmann (org.), Philosophie der Menschenrechte. Frankfurt: Suhrkamp, 1998, p. 29-47. Otfried Höffe, Vernunft und Recht. Bausteine zu einem interkulturellen Rechtsdiskurs. Frankfurt: Suhrkamp, 1996, particularmente o capitulo 3 sobre os direitos humanos (p. 49-82).

Otfried Höffe, Kategonsche Rechtsprinzipien. Ein Kontrapunkt der Modeme. Frankfurt: Suhrkamp,
1990, p. 138.
} 
A troca transcendental, então, é uma troca negativa no sentido de uma troca das renúncias parciais ao uso da própria liberdade.

Höffe dá ao mesmo assunto uma outra formulação, mais clara até: "A limitação da liberdade, então, é trocada por uma garantia de liberdade, a renúncia à liberdade é compensada como uma pretensão de liberdade".

Posto que esses são os pressupostos da argumentação de Höffe, podemos agora começar a analisar sua teoria da troca transcendental. Quero mostrar que o conceito de troca não é adequado no contexto de uma fundamentação dos direitos humanos, e isso por três razões:

1. Primeiro, existem vários tipos de troca, mas o tipo mais comum é a troca do mercado. Quem fala em troca, normalmente se refere a este tipo. Numa troca de mercado, não há, ou não há necessariamente, igualdade de valor entre as mercadorias trocadas. Mais exatamente: a igualdade de valor nem é um critério para uma troca de mercado ser legítima, pois o preço de uma mercadoria depende da relação entre a sua oferta e a sua procura. Höffe, no entanto, parece pressupor a validade do critério da igualdade. Ele diz: "Sob aspectos morais, os direitos humanos se baseiam na regra de ouro, e essa regra é um critério para a justiça da troca." ${ }^{\text {N }}$ No entanto, a regra de ouro não serve justamente no contexto da troca. Se formos num mercado onde podemos negociar o preço, então o negociamos em nosso próprio favor, não a favor do vendedor, como deveríamos, se seguíssemos a regra de ouro. $O$ vendedor, por seu lado, segura o preço dele e evita concessões que lhe sejam desfavoráveis. Mais até: se os atores, no mercado, começassem a comprar e vender seguindo a regra de ouro, o mercado enquanto tal se destruiria ou auto-implodiria. Um elemento central no mercado é a competição, e o uso da regra de ouro num contexto competitivo é autodestruidor.

2. A troca caracteriza-se pelo fato de que ela é voluntánia. Posso trocar uma determinada quantia de reais por uma passagem do Rio de Janeiro a São Paulo, por exemplo. Mas não tenho nenhuma obrigação de fazer essa troca. Segundo Höffe, os direitos humanos criam-se no momento em que todos (os seres humanos) trocam a renúncia parcial ao uso da própria liberdade. Essa troca se efetua no Estado Natural. Mas agora surge uma dificuldade: como podemos explicar o motivo dessa troca? Será que ela é de fato voluntária? Se supusermos que no Estado Natural há pessoas com mais poder e outras com menos, então dificilmente se vê que motivos poderiam levar os mais poderosos a renunciarem também parcialmente ao uso das suas liberdades e poderes. E mesmo se uma tal renúncia ocorrer, seria racional para eles negociarem até que ponto concedem aos outros determinados direitos. Imaginemos alguém conceder aos seus pares a livre escolha da religião em troca da renúncia deles a toda tentativa de tocar à vida dele. Esta troca - liberdade da religião por segurança de não sofrer agressões letais.

Otfried Höffe, Politische Gerechtigkeit. Frankfurt: Suhrkamp, 1989, p. 384.

Otfried Höffe, "Transzendentaler Tausch - eine Legitimationsfigur für die Menschenrechte?" In: S.Gosepath / G. Lohmann (org.), Philosophie der Menschenrechte. Frankfurt/M.: Suhrkamp, 1998, p. $29-47$ (p. 37). 
3. A troca da qual Höffe fala distingue-se da troca no sentido normal da palavra: para poder oferecer alguma coisa numa troca, é preciso dispor dessa coisa em questão. Segundo Höffe, nós trocamos renúncias. Quais são as liberdades às quais nós nos dispomos a renunciar? Matthias Kettner coloca a seguinte questão - com o teor de surpresa: "De onde seria que teriamos algum direito natural a matar os outros? Será que os direitos humanos como os conhecemos devem-se à inversão deste direito singular e universal de ameaçar os outros com violência num direito de estarmos livres deste tipo de ameaça?" ${ }^{5}$

A troca transcendental de Höffe, então, é uma troca pela qual aquilo que é trocado muda de natureza. Antes de efetuarmos a troca, todos têm determinadas liberdades, mas nenhum direito. Depois da troca, todos têm alguns direitos, mas todos têm menos liberdade de que tinham antes. No entanto, se mediante uma interação nasce alguma coisa nova que não existia antes desta interação ocorrer, então essa interação não pode ser uma simples troca. É uma interação criadora de algo, uma interação produtiva, ou seja, uma produção de algo mediante uma colaboração.

Esses três argumentos, então, são suficientes para mostrar que o conceito de troca não pode servir como base de uma fundamentação dos direitos humanos. Proponho que recorramos para isto a um outro conceito, a saber ao conceito de cooperação. Além disto, proponho que não falemos de uma troca (ou cooperação) transcendental, mas sim, de uma procura de argumentos transcendentais que permitam fundamentar os direitos humanos. Para este fim, é preciso procurar as condições necessárias (ou transcendentais) de uma atividade básica para a vida humana. Para Höffe essa atividade básica é a liberdade de ação, pois sem ela não podemos perseguir os nossos interesses. Novamente acho que essa análise não está muito clara, pois uma pessoa pode argumentar que a condição necessária para ela poder perseguir os seus interesses é a dominação das outras pessoas; a liberdade de ação dessa pessoa, então, depende de sua disposição sobre um poder maior das outras pessoas. Porém, essa condição evidentemente não é universalizável. É, então, preciso procurar outra condição necessária, quer dizer, uma condição que seja universal. Essa condição necessária, suponho, é a capacidade de colaborar, uma capacidade que cada um tem ou deve ter. Os direitos humanos, por sua parte, ou pelo menos o núcleo duro desses direitos, constituem as condições necessárias para manter ou esta capacidade de colaborar, ou de adquiri-la.

O que, então, pode-se concluir quanto ao papel do liberalismo e do comunitarismo a partir das considerações feitas acima? Sendo que os direitos humanos são direitos individuais, eles não podem ser tirados dos pressupostos comunitaristas. Isso, desde o começo, pareceu claro. Porém, se a base de uma fundamentação dos direitos humanos é a cooperação - não no sentido de uma instrumentalização

5 Matthias Kettner, "Otfried Höffes transzendental-kontraktualistische Begründung der Menschenrechte". In: Wolfang Kersting (org.), Gerechtigkeit als Tausch?, loc. cit., p. 243-283, p. 243. 
mútua, mas sim como uma interação baseada na regra de ouro, então essa fundamentação, ao mesmo tempo, abre mão da fundamentação do direito de participar em grupos, comunidades, sociedades que cooperam. Não se pode chamar essa posição de liberal, pelo menos não se pode chamá-la assim com mais legitimidade de que chamá-la de comunitarista, pois é salientado o fato de que é o indivíduo quem escolhe o(s) grupo(s) ou a(s) comunidade(s) aos quais ele quer pertencer. Ele tem - ou deve ter - a liberdade de sair de uma tal comunidade em qualquer momento para juntar-se a uma outra, a não ser que com isto ele fira algum direito humano dos seus pares.

A posição à qual chegamos, então, encontra-se a meio caminho entre o liberalismo e o comunitarismo. 